\title{
Oesophageal Adenocarcinoma: A Patient and Physician's Perspective
}

\author{
Derek Maule $\cdot$ Mark Boccola $\cdot$ Reginald V. Lord
}

Received: March 24, 2017 / Published online: April 19, 2017

(C) The Author(s) 2017. This article is an open access publication

\section{ABSTRACT}

This article is co-authored by a patient with oesophageal adenocarcinoma and his physician, who performed oesophagectomy. The patient relates his pre-operative preparation and post-operative experience. The physician comments on the alarming increase in the incidence of this cancer, risk factors, and treatment. As illustrated by the patient's report, the physician also discusses the importance of maintaining adequate nutrition, cardiorespiratory fitness, and a positive psychological attitude.

Keywords: Oesophagectomy; Oesophageal adenocarcinoma; Oesophageal neoplasms; Patient experience; Barrett's oesophagus; Nutrition

Enhanced content To view enhanced content for this article go to http://www.medengine.com/Redeem/ 8608F06017067567.

D. Maule

Sydney, Australia

M. Boccola $\cdot$ R. V. Lord $(\bowtie)$

Department of Surgery, University of Notre Dame

Australia, Sydney, Australia

e-mail: rvlord@stvincents.com.au

\section{PATIENT'S EXPERIENCE}

I was born in the UK in 1940. Apart from a broken arm when I was 9 years old, my most serious illness was TB in the leg in 1954, for which I was treated with streptomycin. After my recovery, I enjoyed playing many sports. Later in life, I took up golf.

I have never smoked. I have never been considered seriously overweight. I enjoy drinking red wine, usually with my evening meal. On retirement, my wife and I emigrated to Australia in July 2006. In early 2008, I occasionally experienced some difficulty swallowing the first mouthful of a sandwich. This difficulty soon passed as I continued eating. It was during a trip to the UK in August 2008 that I suddenly experienced a serious swallowing problem on two separate occasions within 2 days of each other. On our return to Australia, I immediately contacted my GP who arranged for me to have an endoscopy. I had experienced occasional indigestion in the previous few years which was not painful nor could it be considered to be heartburn. Relief was obtained through proprietary indigestion tablets. My GP felt that my swallowing problem could be caused by a hiatal hernia which might have also explained my periodic indigestion when eating rich or spicy foods.

I was referred to a local specialist for the endoscopy. The specialist felt he had seen a cancerous tumour at the lower end of my 
oesophagus. He took biopsies and coloured photographs of the tumour and arranged for me to have a CT and PET scan. I was then referred to Professor R. V. Lord at St Vincent's Clinic, Sydney.

Armed with my full body scan results and photographs taken during the endoscopy, I attended my first consultation with Professor Lord who requested I should have an ultrasound scan and fine needle biopsy taken of the tumour. The biopsy results showed that cancer cells were present in the tumour and surrounding lymph nodes, and I was diagnosed with a Stage II adenocarcinoma. I had no reflux prior to my swallowing discomfort in August 2008. My diagnosis for Stage II oesophageal cancer was made in its early stages and, therefore, the prognosis for successful surgery and recovery was encouraging.

My pre-surgery treatment included a 9-week course of chemotherapy carried out at the Cancer Clinic in Bowral and involved a visit to the clinic on each of the 9 weeks. I did not experience the more extreme side-effects during the chemotherapy treatment; the most obvious being the loss of my head hair and the need for toilet trips in the middle of the night. The nature of the intended surgery was explained to me. I was advised that I might experience some difficulty with breathing and trying to sit up unaided as a result of the surgery. I decided to tone-up the muscles around my chest and abdomen during my chemotherapy course. My son-in-law is a sports trainer, and he devised a simple daily exercise program for me to follow, which had the effect of improving my general physique and gaining a few grams in weight throughout the 9-week chemotherapy course. I had a scientific background as a physicist, so throughout the 9 weeks of treatment, I kept a detailed daily diary recording my weight, blood pressure, exercises, food intake, and general activity including bowel movements to see if there was anything that might be helpful to discuss with my oncologist. The objective of the chemotherapy was to reduce the size of the tumour to make the surgery less invasive. I recall asking my oncologist at the beginning of the treatment whether an improvement in swallowing food was indicative that the tumour size was reducing. Bearing in mind that difficulty in swallowing bread was the only symptom I had before the tests revealed I had oesophageal cancer, I regarded my question as essential for me to maintain the positive outlook I had adopted when my diagnosis was confirmed. After about 4 weeks into the treatment, there was a sudden and noticeable improvement in my ability to eat and swallow food, especially bread. I felt encouraged that the chemotherapy treatment was achieving the objective. It was noted that my weight had increased through the 9-week period. As a result, I am convinced that my immediate recovery period after the surgery was made easier and shorter by being fairly fit before entering hospital. My weight immediately prior to surgery was $82 \mathrm{~kg}(180 \mathrm{lb})$, slightly higher than the average weight for a person of my height, which is $182 \mathrm{~cm}$ [body mass index (BMI): 24 [healthy weight range 18.5-25].

Following my surgery, I undertook physical exercises under the direction of the hospital physiotherapist. Pain management was critical in the days immediately after my surgery. I was connected to an intravenous pump to administer morphine on demand should I require it. I limited the use of the pump to those times when I tried sitting up in bed un-aided. Walking around the wards required a small team of assistants to carry the various tubes and intravenous equipment still attached to me! I was unable to take drink or food for the first 6 days of my recovery. After 6 days, I was given an X-ray after consuming a drink containing a dye to see if my re-engineered digestive system was leaking or not. The results were satisfactory, and I was allowed to drink water for the first time since the surgery. After 6 days, I felt able to sit up in bed without the need for painkillers and this facility was removed. My food intake was restricted to clear soup and jelly. I continued walking around the wards and taking exercises until my discharge from hospital. I was hospitalised for a total of 9 days. My weight at the time of being discharged from hospital was $67 \mathrm{~kg}$ (147 lb; BMI: 20). I am convinced that undertaking a program of physical exercises prior to my oesophageal cancer surgery contributed to my relatively short hospitalised recovery period. 
After the surgery, I agreed to undertake another 9-week course of chemotherapy recommended as "insurance" against any lingering cancer cells remaining from the surgery. The second course of treatment was exactly the same as the first. Although I had a reasonable experience during the pre-surgery chemotherapy course, I did feel much weaker during the post-surgery chemotherapy and felt the need for a mid-afternoon nap each day. Again, I seemed to escape most of the possible side-effects of chemotherapy except for the loss of my body hair for the second time and the regular nightly toilet trips! I continued to keep up my morning exercises and kept a daily diary as before throughout the 9-week course in case there was anything significant to discuss with my oncologist. After the 9-week course, I encouraged myself to believe that I was now on the way to a speedy and complete recovery.

On reflection, I probably tried too hard too soon to get back to the eating habits I had prior to my swallowing problem of August 2008, and as such, I found difficulties in understanding how my re-engineered digestive system might react to certain foods, including the quantities contained in specific meals and my subsequent bowel movements, which lacked consistency through most days. I even graded my daily bowel movements on a scale from 1 to 5 to monitor any pattern that may have been established. I was probably guilty of having expectations that exceeded the reality of my situation, and I soon realised and accepted that I needed to develop more patience throughout the period of my post-surgery recovery, which was clearly taking much longer than I had anticipated.

I enjoyed normal meals, including those containing red or white meat and vegetables. However, 5 months after my surgery and on rare occasions, I developed hiccups after the first mouthful and I experienced some discomfort and difficulty in swallowing and could not continue my meal until I cleared what appeared to be trapped wind in my stomach. The phenomenon was unpredictable. I took this as a wake-up call either to chew each mouthful of food for longer or to slow down the rate at which I tried eating my food. The symptoms of the swallowing problem were similar to when I had the blockage the previous year due to oesophageal cancer but the fact that I was able to resume normal eating after clearing the stomach wind suggested that my discomfort was a form of reflux rather than any physical problem with my re-engineered digestive system. To ease the situation further, my GP prescribed a proton pump inhibitor (omeprazole), which I continue to take daily, and this seemed to gradually improve my ability to eat well consistently without the fear of reflux. My bowel movements varied from passing normal stools early each morning to much looser movements some $3 \mathrm{~h}$ later after which I felt quite exhausted and debilitated. This discomfort continued for 3 years after my surgery and is sometimes called "late dumping syndrome", which I understand is not uncommon for patients who have undergone intestinal surgery.

Another painful episode was due to the phenomenon unknown to me at the time called adhesions. My first experience occurred 8 months after my surgery whilst driving. I suddenly had excruciating pains in my lower abdomen, which remained with me for $24 \mathrm{~h}$. During this time, I felt constipated and vomited several times before the pain subsided. I avoided eating any solid food for $24 \mathrm{~h}$ and visited my GP, who arranged for X-rays to determine whether there was any blockage in my system. Fortunately, the results were satisfactory, and my GP explained adhesions and how they formed after internal surgery and sometimes break away causing minor blockages and subsequent pain. Twelve months after the first painful experience, I suffered another similar painful effect of adhesions for $24 \mathrm{~h}$ and was able to recognise the symptoms. Although I was in some discomfort for that period, I did not have the fear-factor and the discomfort soon passed. Over the following 2 years or so, I experienced lesser periods of discomfort, similar to the first two attacks, but with less pain and for a shorter time until eventually, the discomfort stopped.

I do sometimes experience some physical discomfort from adhesions, which have made the internal area around my liver and stomach "sticky", and I feel the occasional need to 
stretch to maintain the flexibility around the surgery scars, mainly at the bottom of my right rib cage and lung. I attend a weekly yoga class, which lessens the tightening effect I sometimes experience from the scars around the side of my body where the main surgical incisions were made. I occasionally experience an effect where my voice appears to break whilst speaking due to mild acid reflux causing the occasional inflammation of the throat. I also have some numbness in my big toes, which is caused by nerve damage from the platinum in one of the chemotherapy agents. However, these are mild discomforts that I recognise and I am able to manage, causing no limitations or restrictions on my life style.

It is over 8 years since the symptoms of my oesophageal cancer first appeared in 2008. I have an annual gastroscopy to inspect and take biopsies from my oesophagus. I continue to take omeprazole daily to prevent reflux, and I use three pillows in bed to ensure that my head remains higher than the rest of my body to minimise the possibility of acid reflux during the night. I eat regular meals and take a mid-morning and mid-afternoon snack with my coffee or tea. I consider myself to be as fit as I possibly could be after my surgery which I attribute to the excellent medical treatment I have received and to my positive outlook for the future. If there are two lessons I have learned from my experience with oesophageal cancer, they are the need for pre-surgery preparation and post-surgery patience.

\section{PHYSICIAN'S PERSPECTIVE}

Mr. Maule's description of his experience with oesophageal cancer is written in a remarkably clear, straightforward fashion. He had an esophageal adenocarcinoma (EAC), which was a rare cancer throughout most of recorded medical history, but has become increasingly more common during the latter half of the twentieth century. Indeed, for reasons that remain unknown, the incidence of EAC has increased at a rate greater than any other cancer in recent decades, with a more than sixfold increase in the United States.
Mr. Maule's story includes some valuable information for those with EAC and also for those working to improve the outlook for patients. Consistent with the presumed multistage carcinogenesis model for EAC, his tumor developed in a segment of Barrett's esophagus. Chronic severe gastroesophageal reflux disease is the major etiological factor for Barrett's disease, but Mr. Maule denies having had any typical reflux symptoms. He experienced "indigestion" shortly before the EAC diagnosis, but does not give a history of heartburn or regurgitation. In the absence of upper gastrointestinal symptoms he had not undergone endoscopy prior to the cancer diagnostic endoscopy and consequently, like most individuals with Barrett's esophagus, he was unaware that he had Barrett's disease.

This illustrates a major problem for improving the current dismal survival statistics for EAC: although the cancer is usually curable when diagnosed early in patients with known Barrett's esophagus who undergo surveillance endoscopy, most patients with Barrett's are undiagnosed as they have not had endoscopy. Since the cost of endoscopy precludes population screening, novel non-endoscopic diagnostic strategies are needed. In this regard, many research teams are seeking a less invasive, less expensive diagnostic test, such as a blood test for Barrett's esophagus, EAC, or both.

Besides the major risk factor of Barrett's esophagus, Mr. Maule is also male, age over 60 years, and has Caucasian ancestry as risk factors for EAC. EAC has one of the strongest associations with obesity, but he had never been seriously overweight and he had never used tobacco, another risk factor. He enjoys drinking red wine, which, like alcohol use in general, does not increase risk of EAC.

Mr. Maule presented with dysphagia, in his case with a sandwich. Bread, meat, and rice are common precipitants of solid food dysphagia. When patients present with dysphagia this is usually a sign that more than $60 \%$ of the esophageal circumference is involved by cancer and the luminal diameter is less than $12 \mathrm{~mm}$.

One interesting aspect of Mr. Maule's account is that soon after receiving his cancer diagnosis he began to improve his physical 
condition in preparation for esophagectomy. This is recommended for all patients, but few adopt this suggestion with the same diligence. His son-in-law, a professional sports trainer, devised an exercise program to improve fitness in general and core thoraco-abdominal and respiratory fitness in particular. As Mr. Maule writes, his immediate postoperative recovery seems likely to have been easier and shorter through being fit prior to surgery. It has been difficult to prove that such measures provide a significant benefit: a non-randomized study of patients undergoing esophagectomy found that inspiratory muscle training, which includes deep breathing exercises, incentive spirometry, and other activities, improved respiratory function, but not surgical outcomes [1]. Similar results are found for other operations, but study quality is mostly low for these reports. As recommended by a Cochrane review, there is an urgent need for high quality, adequately powered, randomized trials [2].

Displaying the traits of his past career in physics, Mr. Maule also kept a diary recording daily food intake, weight, and other factors. Unusually, he was able to gain weight during the pre-operative chemotherapy treatment period. The importance of nutrition in patients with esophageal cancer and malnutrition due to dysphagia, weight loss, and cachexia, is widely accepted [3, 4]. For patients without obvious malnutrition, like Mr. Maule, there are no compelling data regarding nutritional supplementation, but it is recommended that enhanced enteral nutrition should be provided during chemo- and radiotherapy treatment [5]. Immune-enteral nutrition may be especially beneficial; pre-operative provision of specialized nutritional support with immune-modulating nutrients reportedly results in less post-operative morbidity and is cost-effective for major operations, including esophagectomy [6].

Mr. Maule refers to the positive attitude he adopted at the time of diagnosis and how he was able to maintain this attitude throughout the arduous treatment, for example by focussing on his improved swallowing during chemotherapy treatment. Attributes such as hope and optimism regarding the future, part of the wider field known as positive psychology, have become areas of increased research interest in the past two decades. Adopting a "positive attitude" is believed by many to help with managing the emotional, psychological, social, economic, and relationship difficulties that arise with a cancer diagnosis. An optimistic outlook may be associated with more active coping strategies $[7,8]$. Reports on esophageal cancer patients are awaited, but optimism level predicted survival at 1 year after head and neck cancer diagnosis in one study [9], and in another study patients who were assessed as being more optimistic generally coped better with a diagnosis of early breast cancer than those who were more pessimistic [10].

Regarding his operative treatment, $\mathrm{Mr}$. Maule underwent esophagectomy with en bloc lymphadenectomy. This extensive operation is not performed by most surgeons. None of the 43 lymph nodes removed in his case showed involvement by cancer on histopathological examination of the resection specimen. Mr. Maule can be considered cured as he has survived well beyond 5 years after treatment, and in retrospect a less extensive operation would probably also have cured this cancer-but lymph node involvement is difficult to assess with certainty pre-operatively. Reports from other surgeons who perform an en bloc esophagectomy indicate that this operation provides the highest likelihood of surgical cure [11], especially for those with metastasis to a limited number of lymph nodes (estimated at up to 8 nodes) $[12,13]$. This article does not contain any new studies with human or animal subjects performed by any of the authors.

\section{ACKNOWLEDGEMENTS}

No funding or sponsorship was received for publication of this article. All named authors meet the International Committee of Medical Journal Editors (ICMJE) criteria for authorship for this manuscript, take responsibility for the integrity of the work as a whole, and have given final approval for the version to be published. The opinions expressed in the manuscript are those of the authors. 
Disclosures. Derek Maule, Mark Boccola and Reginald V. Lord have nothing to disclose with regards to the publication of this article.

Compliance with Ethics Guidelines. This article does not contain any new studies with human or animal subjects performed by any of the authors.

Peer Review. Please note, contrary to the journal's standard double-blind peer review process, as a commentary this article underwent review by a member of the journal's editorial board.

Open Access. This article is distributed under the terms of the Creative Commons Attribution-NonCommercial 4.0 International License (http://creativecommons.org/licenses/ by-nc/4.0/), which permits any noncommercial use, distribution, and reproduction in any medium, provided you give appropriate credit to the original author(s) and the source, provide a link to the Creative Commons license, and indicate if changes were made.

\section{REFERENCES}

1. Dettling DS, van der Schaaf M, Blom RLGM, Nollet F, Busch ORC, van Berge Henegouwen MI. Feasibility and effectiveness of pre-operative inspiratory muscle training in patients undergoing oesophagectomy: a pilot study. Physiother Res Int J Res Clin Phys Ther. 2013;18(1):16-26.

2. Bond-Smith G, Belgaumkar AP, Davidson BR, Gurusamy KS. Enhanced recovery protocols for major upper gastrointestinal, liver and pancreatic surgery. In: The Cochrane Collaboration, editor. Cochrane database of systematic reviews. Chichester: Wiley; 2016 [cited 2017 Feb 6]. doi:10.1002/14651858. CD011382.pub2.

3. Bozzetti F. Nutritional support in patients with oesophageal cancer. Support Care Cancer Off J Multinatl Assoc Support Care Cancer. 2010;18(Suppl 2):S41-50.

4. Nozoe T, Kimura Y, Ishida M, Saeki H, Korenaga D, Sugimachi K. Correlation of pre-operative nutritional condition with post-operative complications in surgical treatment for oesophageal carcinoma. Eur J Surg Oncol J Eur Soc Surg Oncol Br Assoc Surg Oncol. 2002;28(4):396-400.

5. Arends J, Bachmann P, Baracos V, Barthelemy N, Bertz H, Bozzetti F, et al. ESPEN guidelines on nutrition in cancer patients. Clin Nutr. 2016 Aug [cited 2017 Feb 6]. http://linkinghub.elsevier.com/ retrieve/pii/S0261561416301819.

6. Wong CS, Aly EH. The effects of enteral immunonutrition in upper gastrointestinal surgery: a systematic review and meta-analysis. Int J Surg. 2016;29:137-50.

7. Carver CS, Scheier MF. Dispositional optimism. Trends Cogn Sci. 2014;18(6):293-9.

8. Rasmussen HN, Scheier MF, Greenhouse JB. Optimism and physical health: a meta-analytic review. Ann Behav Med Publ Soc Behav Med. 2009;37(3): 239-56.

9. Allison PJ, Guichard C, Fung K, Gilain L. Dispositional optimism predicts survival status 1 year after diagnosis in head and neck cancer patients. J Clin Oncol Off J Am Soc Clin Oncol. 2003;21(3):543-8.

10. Carver CS, Smith RG, Antoni MH, Petronis VM, Weiss S, Derhagopian RP. Optimistic personality and psychosocial well-being during treatment predict psychosocial well-being among long-term survivors of breast cancer. Health Psychol Off J Div Health Psychol Am Psychol Assoc. 2005;24(5): 508-16.

11. Peyre CG, Hagen JA, DeMeester SR, Altorki NK, Ancona E, Griffin SM, et al. The number of lymph nodes removed predicts survival in esophageal cancer: an international study on the impact of extent of surgical resection. Ann Surg. 2008;248(4): 549-56.

12. Johansson J, DeMeester TR, Hagen JA, DeMeester SR, Peters JH, Oberg S, et al. En bloc vs transhiatal esophagectomy for stage T3 N1 adenocarcinoma of the distal esophagus. Arch Surg. 2004;139(6): 627-33.

13. Omloo JMT, Lagarde SM, Hulscher JBF, Reitsma JB, Fockens $\mathrm{P}$, van Dekken $\mathrm{H}$, et al. Extended transthoracic resection compared with limited transhiatal resection for adenocarcinoma of the mid/distal esophagus: five-year survival of a randomized clinical trial. Ann Surg. 2007;246(6): 992-1001. 